\title{
EL V CONGRESO DEL PARTIDO COMUNISTA DE CUBA
}

\author{
Felipe Ruiz Alonso*
}

El V Congreso del Partido Comunista cubano se ha desarrollado entre los días 8 y 10 de octubre de 1997 en un ambiente conmemorativo del trigésimo aniversario de la muerte del Che Guevara y sus compañeros guerrilleros. Precisamente este año, 1997, se dedicaba al recuerdo de este acontecimiento, lo mismo que el Congreso que se celebraba seis años después del anterior. Normalmente el tiempo previsto para la celebración de los Congresos es cada cinco años. A este Congreso asistieron 1.500 delegados que durante tres días escucharon las diversas intervenciones y votaron y aprobaron las resoluciones que les fueron sometidas sobre el Partido Comunista, con el extraño título: "El Partido de la unidad, la democracia y los derechos humanos que defendemos". Otras resoluciones se presentaron sobre los Estatutos del Partido y sobre la situación económica.

La celebración de un Congreso es un acontecimiento netamente político, y en este sentido las miras del mundo entero estaban puestas en las posibles reformas que podrían introducirse en el rumbo de la política cubana. El papel hegemónico del Partido Comunista Cubano determina la orientación de la política interior y exterior cubana, así como la actividad económica, social y cultural, de ahí la importancia de las conclusiones. Las circunstancias que rodeaban este Congreso eran favorables para prever algunas reformas en el sector económico y seguramente en la organización política. La industria azucarera, la más importante del país, ha caído a niveles de producción muy bajos, 4.3 millones de toneladas, frente a los 7 ú 8 de la década de los ochenta. Siendo este el renglón más importante de la producción cubana requería un análisis muy profundo de las circunstancias tanto económicas como políticas, objetivas y subjetivas, internas o externas, que han llevada a este fracaso histórico de la producción cubana. La deuda exterior elevada hasta los 10.000 millones de dólares tampoco permite al país acceder a créditos blandos favorables. A esto se añaden las imposiciones de la ley Helms-Burton, que encarecen los precios y los préstamos.

En el ámbito político no era fácil prever modificaciones, ni siquiera por causa de los 71 años de Fidel Castro y las suposiciones de una quebrantada salud. La acumulación de los más importantes cargos de Estado sobre sí, Secretario General del Comité Central del Partido Comu- nista, Presidente del Consejo de Estado y del Consejo de Ministros, y Comandante en Jefe del Ejército, no era fácil que pudieran sufrir alteraciones.

El V Congreso se celebró a pocas fechas de la visita del Papa Juan Pablo II que, necesariamente, iba a determinar un antes y un después de dicha visita pensando en el protagonismo que pueda ejercer una Iglesia jerarquizada que tiene una determinada fuerza en el interior y mucha influencia desde el exterior de la Isla.

Han transcurrido seis años desde el IV Congreso (1991) y en esos años ha habido una evolución de las relaciones internacionales donde el sistema comunista de socialismo real ha quedado prácticamente desaparecido y los apoyos cubanos en el exterior han cambiado de signo político. El aislamiento que constataba el IV Congreso ha producido sus efectos negativos porque Cuba ha tenido que atravesar un quinquenio muy doloroso de escasez y penalidades. A ello hay que unir que en el período de seis años se han tomado algunas medidas consideradas importantes en Cuba, como son Reforma de la Constitución en 1992, la nueva Ley Electoral del mismo años, y la composición de la nueva Asamblea Nacional fruto de las reformas anteriores

En este período, también entre Congresos, se han sucedido dos acontecimiento que han representado un ataque muy directo a la economía cubana: en 1992 se aprobaba la Ley Torricelli por los Estados Unidos (Cuban Democracy Act) y en 1996 de Ley Helms-Burton (Cuban Liberty and Democratic Solidarity Act). Estas dos leyes han pretendido aplicar restricciones más duras para el establecimiento de relaciones comerciales con Cuba de tal manera que el Gobierno cubano tuviera que verse forzado a realizar los cambios políticos necesarios para equiparar su sistema al modelo deseado por los Estados Unidos.

\section{EL RECUERDO DEL IV CONGRESO}

El IV Congreso se celebró en 1991, entre los días 10 y 14 de octubre, y había estado precedido de varios meses de

* Universidad Pontificia de Salamanca. 
preparación recogiendo las principales inquietudes populares que serían objeto de estudio y consideración en las diversas resoluciones que se presentaron. Las principales demandas populares presentadas después de numerosos debates realizados a todo lo largo de país podrían resumirse en cinco puntos:

- Democratización de las instituciones políticas del país, en especial del Partido Comunista Cubano y la Asamblea Nacional.

- Eficacia de los mecanismos de representación política: especialmente las elecciones.

- Lucha contra la discriminación de los creyentes religiosos.

- Promoción de la mayor participación de jóvenes, mujeres y negros en los organismos de dirección del país.

- Reformas a favor de la descentralización, la eficiencia económica y mayor participación popular en las decisiones.

Aquel Congreso, que era el primero después de la desaparición del campo socialista, aparecía con una fuerte carga crítica por parte de los sectores populares y reclamaban una labor de cambios estructurales. El IV Congreso despertó más interés y atención por parte de la ciudadanía. Se esperaban grandes cambios y esto hizo que la participación precongresual se cifrara en más de un millón de propuestas a las diferentes resoluciones que se presentaban al Congreso. Pero algunos líderes de la Revolución se encargaron de rebajar los intentos críticos. José Ramón Machado Ventura, del Buró Político, se quejaba de "la mala preparación de algunos organismos de base a la hora de discutir el llamamiento al IV Congreso" ', por haber generado "planteamientos desacertados, hipercríticos, incompatibles con nuestros principios". No obstante se percibía un ambiente propicio para las reformas al aceptar que la "sociedad estaba madura para cambios" y, por lo tanto, había que "perfeccionar el socialismo" ${ }^{2}$.

En las resoluciones presentadas y aprobadas por el IV Congreso se preveía, como medida más sustancial, la modificación de la Constitución para hacer posible la introducción de un nuevo sistema electoral que propiciara una participación más directa del electorado en las elecciones de diputados para la Asamblea Nacional ${ }^{3}$. Era el momento de eliminar de la Constitución las alusiones a la Unión Soviética y a los países de la comunidad socialista como modelos de la Revolución cubana.

Después del IV Congreso, y una vez aprobada la nueva Constitución ${ }^{4}$, se celebraron elecciones a las Asambleas Provinciales y Nacional aplicando los procedimientos expresados en el Congreso y plasmados en la nueva Ley Electoral $^{5}$ de 1992 mediante un sistema de voto directo y secreto para la elección de Diputados. Todo ello dista mucho de cualquier homologación con un sistema electoral libre y abierto con pluralidad de partidos políticos, ya que en lo más alto de los principios del socialismo cubano se mantiene la hegemonía del Partido Comunista como partido único ${ }^{6}$.

\section{DESARROLLO DEL V CONGRESO}

El V Congreso se ha desarrollado durante tres días y, aunque pertenecían al mismo 1.500 delegados, nunca han asistido la totalidad de los mismos. En todo caso, los militantes del Partido reciben previamente las resoluciones que se van a presentar al Congreso y han podido previamente, sean o no delegados, presentar alegaciones o propuestas para ser introducidas en los textos que se presenten a la aprobación de los delegados.

En el escenario del Congreso figuraban como símbolo e inspiradores ideológicos, cinco grandes fotografías de Marx, Lenin, Martí, Mella y el Che. El lema que presidía la reunión era una frase de Fidel Castro: "Este pueblo, este partido, jamás entregará su unidad”. Contrastan los símbolos y los lemas entre los dos últimos Congresos. En el IV Congreso solamente aparecían las fotografías de Marx y Martí, y el lema decía: "Nuestro deber más sagrado: Salvar la Patria, la Revolución y el Socialismo".

El primer día se dedicó a la presentación del Informe Central, consumiendo Fidel Castro gran parte de su duración con una intervención de siete hora. La parte sustancial del Congreso continuaba con la presentación, discusión y aprobación de las resoluciones del Congreso y la revisión de los Estatutos del Partido. José Ramón Machado Ventura, miembro del Buró Político, al presentar la Resolución sobre la Reforma de los Estatutos del Partido solicitó que se realizaran algunas modificaciones para adecuarse a las nuevas realidades ${ }^{7}$. No se propusieron modificaciones significativamente importantes. El segundo día del Congreso estaba prevista la presentación de candidaturas para el Comité Central ${ }^{8}$ y la realización de la votación. La reunión del pleno del Comité Central y el discurso final de clausura, correspondiente al Primer Secretario del Comité Central, Fidel Castro, se celebró el último día.

En el Congreso fue ratificado Fidel Castro al frente de la organización y Raúl Castro fue designado Segundo

1. Granma, La Habana 28-I-1991. Pág. 3.

2. Ibid.

3. La presentación de estas reformas fueron defendidas por Carlos Aldana, quien a la sazón era presentado como el ideólogo del Partido y ocupaba el número tres en el escalafón del poder dentro del Partido. Un año después era expulsado del Partido por verse implicado en negocios fraudulentos.

4. La nueva Constitución cubana sustituía a la primera Constitución Socialista de 1976 y se reformó en las sesiones de la Asamblea Nacional los días 10, 11 y 12 de julio de 1992, publicándose en la Gaceta Oficial de la República de Cuba el 1) de agosto de 1992. Consta de 137 artículos.

5. La Ley Electoral vigente en Cuba fue firmada por el Presidente de la Asamblea Nacional, Juan Escalona Reguera el 29 de octubre de 1992 y publicada en la Gaceta Oficial de la República de Cuba el 2 de noviembre de 1992.

6. El Art. 5 de la Constitución de 1992 establece que "El Partido Comunista de Cuba... es la fuerza dirigente superior de la sociedad y del Estado, que organiza y orienta los esfuerzos comunes hacia los altos fines de la construcción del socialismo y el avance hacia la sociedad comunista".

7. "La unidad es el arma indestructible del pueblo", en Granma, La Habana, 9-X-97. Pág. 6.

8. El Comité Central se ha reducido de 225 a 150 miembros. En el mismo se encuentran miembros de tres generaciones: los que hicieron la Revolución, los que vivieron la Revolución, y los que nacieron con la Revolución. 
Secretario. También fue seleccionado un nuevo Buró Político formado por 24 miembros, de los cuales 18 son reelegidos y 6 ingresaron por primera vez. En las elecciones al Comité Central se redujo a 150 en número de sus miembros para aplicar los criterios de eficacia y reducción de gastos.

Con relación al interés suscitado en la ciudadanía la celebración de este Congreso, la agencia de noticias independiente Cuba Press manifestaba que era escaso pues se sabía de antemano que "lo único que se puede esperar del mismo es el mantenimiento del poder represivo, característico de la dictadura" $"$.

\section{EL INFORME CENTRAL AL V CONGRESO}

Como es preceptivo, corresponde al Primer Secretario del Comité Central la presentación de este informe, y de ello se encargó el propio Fidel Castro, con la amplitud habitual y una duración casi siete hora. La rumorología de las vísperas hablaba de una enfermedad del Presidente cubano y se convirtió en noticia la gran duración del mensaje. El contenido del mismo hizo repaso a la situación del país, los problemas más acuciantes, las soluciones previstas, una crítica al modelo capitalista, y palabras de aliento para el mantenimiento del modelo socialista emprendido por la Revolución. Serviría, también, para rendir un homenaje al Che Guevara, cuyos restos acababan de llegar procedente de Bolivia, y "que se sentiría orgulloso, decía Fidel Castro, de los méritos y virtudes de este pueblo, de su voluntad y de su heroísmo" ${ }^{10}$.

El Informe Central de Fidel Castro no constituye una exposición rigurosa redactada previamente para la ocasión, porque, como él mismo dice, se trata de una serie de notas apuntadas, fruto de la lectura de múltiples documentos, que desea presentar y comentar a los congresistas. Fidel Castro no es muy partidario de la lectura pesada de largos documentos y en este sentido siempre se ha destacado por la oratoria y el comentario más o menos informal. De hecho, en el discurso de clausura hubo de precisar que no se había olvidado mencionar a la Federación de Mujeres Cubana, puesto que utilizó el calificativo cariñoso y familiar de "mujeres", para referirse a ellas, "porque para mí las mujeres y la federación es la misma cosa" ".

\section{DIFICULTADES ECONÓMICAS ENTRE EL IV Y V CONGRESO}

Fidel Castro destaca que el principal problema surgido entre los Congresos de 1991 y 1997 ha sido la desaparición de la Unión Soviética. Cuando se clausuró el IV Congreso ya había desaparecido el campo socialista y quedaba la URSS, pero Castro preveía lo peor: "yo tenía ya la convicción de que la Unión Soviética también desaparecería” ${ }^{12}$.

Se señalan una serie de incumplimientos por parte de la Unión Soviética que teniendo que suministrar más de 700 productos, fueron eliminándose poco a poco hasta suministrar únicamente el combustible. Entre los produc- tos suprimidos que han producido mayor daño a la economía cubana se citan los cereales para la producción de piensos, la mantequilla, el aceite, la manteca, el arroz, la carne en conserva, el pescado, los fertilizantes, el acero, la madera, la sosa cáustica, el carbonato de sodio, los neumáticos, y el algodón. El mayor problema de alguna de estas limitaciones es que muchas industrias cubanas dependían de estas materias primas para poder operar, y en otros casos se resentía directamente el mercado de abastecimientos para la población ${ }^{13}$.

El único producto que la antigua Unión Soviética ha estado proporcionado a Cuba ha sido el combustible, pero a precio del mercado mundial. Pero aún en estos suministros, a partir de 1992, se produjo una reducción con relación a lo acordado, lo que perjudicó a todos los sectores de la economía.

La situación de escasez ha sido el drama más duro de la Revolución en toda su historia y ha correspondido a esta fase entre Congresos que ha sido destacada ampliamente por el Informe Central. "La agricultura se quedó sin el combustible necesario para un mínimo de actividades, sin fertilizantes, sin pesticidas ni herbicidas, sin piezas de repuesto... No se podía mantener la producción alimentaria... La industria mecánica se quedó sin aceros, sin motores, sin los cambios de productos que necesita para su trabajo... La industria ligera se quedó sin algodón, sin infinidad de materiales que necesitaba para la producción de telas... La prensa se quedó sin papel... El transporte se quedó sin piezas... sin motores... les pasó lo mismo a las locomotoras y a los servicios de transporte ferroviario; empezamos a tener problemas con el transporte naval" ${ }^{14}$. Las importaciones se redujeron de 8.139 millones de dólares en 1989 a 2.136 millones de dólares en 1992.

Se ha visto afectados otros servicios que son más sensibles a la propagada de la Revolución, como la educación, la sanidad y la vivienda. Para estos se aplicó un sistema de priorizaciones, pero aún así "la educación se quedó sin libros de texto", "la industria de materiales de construcción se quedó sin combustible suficiente, sin materias primas, sin piedra, sin arena, sin cementos... La situación afectó, también a "la industria de medicamentos" por la carencia de "materias primas para producir medicamentos y los medios necesarios para la atención higiénica, la limpieza de hospitales, la reparación y el mantenimiento de los equipos" ${ }^{15}$.

\section{SOLUCIONES PROPUESTAS}

Como primera medida, el Informe Central estima que se hizo todo lo que era necesario "sin renunciar a los principios". El lenguaje resulta un tanto apocalíptico frente a

9. "Actualidad cubana", en Noticias de Cuba: http: //www.canfinet.orga/spanish/press/c971103a.htm.

10. Granma, Informe Central. La Habana, 29-X-97. Pág. 14.

11. Ibid. Pág. 3.

12. Ibid.

13. Ibid.

14. Ibid. Pág. 4.

15. Ibid. Pág. 4 
la triste situación descrita y que afectó críticamente a los años que van de 1992 a 1996. "Era necesario buscar fórmulas, soluciones, innovar, crear; era necesario perfeccionar la obra de la Revolución, era necesario mejorarlo todo, era necesario buscar eficiencia en todos los sentidos, era necesario encontrar soluciones a corto, a medio y a largo plazo" ${ }^{16}$. Cuba se encontraba desde los años ochenta en un "período especial" proclamado para los tiempos de amenaza de invasión norteamericana, pero ahora se situaba en "período especial en tiempo de paz". Esto reclamaba una atención mayor a los mecanismos de producción y a la consecución de eficacia, aferrados de una manera más acrecentada a los principios y a las ideas revolucionarias. De suscitar estas condiciones subjetivas se encargaron la propaganda sistemática del Partido y los llamamientos de sus líderes, especialmente el mismo Fidel Castro.

En el lenguaje triunfalista del Informe Central se entrevé una mejora en la situación derivada del "período especial en tiempo de paz", relacionado con una pretendida "gran dosis de paciencia" y con una nueva actitud practicada en los últimos años donde se ha mostrado claramente una disposición para aceptar la cooperación exterior. Las nuevas realidades han forzado la situación y permiten afirmaciones imposibles en otros Congresos anteriores: "Estamos abiertos a todas las posibilidades y examinamos todas las experiencias... nosotros, en este mundo de hoy, tenemos que estar en contacto con el mundo y con sus realidades" ${ }^{17}$. A renglón seguido, y para consumo interno, Fidel Castro marca los límites a esta disposición aperturista y promete a los congresista que no aceptará la rendición, ni la renuncia al socialismo, ni la renuncia a las conquistas de la Revolución, ni la cesión de soberanía, independencia, o aceptación de imposiciones. Corresponde al Partido, se dirá, el trabajo, la innovación, el perfeccionamiento de la obra y el hacer las concesiones necesarias. Se acepta, incluso, que se han hecho concesiones ya.

Entre estas concesiones admitidas, algunas ocupan el lugar del deber y otras de la necesidad. No todas han sido aceptadas de buen grado y entre ástas se encuentra el turismo. Este es uno de los renglones que está aportando a Cuba una mayor remesa de divisas y se ha convertido en la industria más desarrollada en los últimos años. Fidel Castro manifiesta clara y resignadamente en el Informe Central que... "no nos gustaba mucho el turismo, todos lo sabemos; sin embargo... es deber nuestro estar preparados para saber utilizar todas las cosas positivas que tiene, y en contacto con el mundo, no "enclaustrarnos" 18

Tampoco gustaba mucho al Gobierno de Cuba la inversión extranjera, pero las exigencias del desarrollo y la necesidad de capital requerían la aceptación de la misma. Esto pone a Cuba en contacto con el mundo capitalista y aquí es donde se debate el dilema entre el deber y la necesidad, elevar lo excepcional a regla. En el Informe Central se justifica la aplicación de métodos nuevos para perfeccionar la obra de la Revolución. Se necesitan tecnologías nuevas, que están en manos del mundo capitalista, y se necesitan mercados nuevos en el mundo capitalista. Incluso se reconoce que en el mundo capitalista se dan experiencias, organización, administración y métodos que hay que copiar y aceptar. La fórmula que se ha empleado es la de las empresas mixtas. "Era necesaria la presencia de capital extranjero para un desarrollo más integral y más completo de nuestro país, dice Fidel Castro, para resolver problemas tecnológicos, adquirir experiencias, abrir mercados" ${ }^{19}$.

En el orden interno también se han producido cambios, que han resultado dolorosos en otros momentos. Se ha tenido que volver a abrir a la iniciativa privada un mercado campesino que ya supuso una marcha atrás en años anteriores ${ }^{20}$. Se han entregado tierras para el cultivo del tabaco, el café, y se impulsaron los huertos familiares. Se han creado las "unidades básicas de producción cooperativa” (UBPC) donde los agricultores reciben en usufructo las tierras y reciben la maquinaria y créditos para la producción. Aunque estas fórmulas son más socialistas que comunistas, la medida ha pretendido estimular al agricultor buscando la eficiencia mediante la vinculación entre la producción y el ingreso personal.

La despenalización de la tenencia de divisas ha caracterizado otras de las medidas nuevas que ha permitido la existencia de una red de tiendas y servicios de comida que introducen el área del dólar en abierta competencia con el peso. "Calculen, dice Fidel Castro, cuanto tiene que habernos dolido este tipo de remedio, la existencia de dos monedas, a una de las cuales tiene acceso sólo una parte de la gente, por una razón o por otra" ${ }^{21}$.

\section{LAS MEDIDAS POLÍTICAS}

El Informe Central no es capaz de aportar cambios significativos en lo que a innovaciones políticas se refiere. A pesar de las numerosas recomendaciones en los foros internacionales latinoamericanos o europeos para que el Gobierno cubano introduzca algunas reformas conducentes a una "transición" hacia la mayor participación política, el Partido Comunista Cubano sigue considerándose como Partido hegemónico y las únicas innovaciones introducidas hacen referencia a los nuevos métodos de control en el aparato administrativo y la creación de sistemas de inspección y auditoría. Con este propósito se crearon la Oficina Nacional de la Administración Tributaria y la Oficina Nacional de Auditorías.

Los motivos alegados para la introducción de estas ligeras modificaciones, que no se orientan hacia un cambio para mayor participación democrática son, la eficacia, el ahorro, el control de las cuentas y el establecimiento de impuestos para aquellos que trabajan por cuenta propia, los alquileres, y el mercado agropecuario. Obedece, por lo tanto, a una mayor eficacia del trabajo tanto del Estado

16. Ibid. Pág. 5.

17. Ibid.

18. Ibid.

19. Ibid.

20. En el IV Congreso fue rechazada por unanimidad la apertura a mercados libres campesinos porque creaban desigualdades, pero fueron abiertos por decreto ley en octubre de 1994 después de la llamada "crisis de los balseros".

21. Granma, Informe Central, La Habana, 29-X-97. Pág. 5. 
como de los Poderes Populares, en vistas de las concesiones introducidas en las actividades económicas de carácter privado.

Plantea la lucha contra Cuba como una guerra económica y apela al espíritu del soldado para enfrentar esa lucha, elogiando el papel de las Fuerzas Armadas Revolucionarias por su "aportación al ahorro de recursos humanos y materiales, así como su contribución al desarrollo de la capacidad defensiva, la preparación del pueblo y sus experiencias en la administración de recursos" ${ }^{22}$. También elogió la labor del Ministerio del Interior "en su lucha contra la delincuencia”, entre cuyas actividades se entiende la seguridad del Estado y el control de la disidencia.

\section{LA SITUACIÓN EN EL AÑO 1997}

En los últimos años el crecimiento ha sido positivo observándose que en el año 1994 ya se detenía el descenso de la economía. En el año 1995 el avance fue de un 2,5 y en 1996 se creció un 7,8. En ese año creció la producción azucarera de unos 3,3 millones de toneladas a un 4,4. Estos índice de producción son muy bajos, en comparación con los de los años ochenta que se encontraban entre los 7 y los 8 millones de toneladas, y la producción del año 1992 fue de 7 millones de toneladas. Para el año 1997 se supone que la cosecha todavía era mala.

Entre los factores que influyen en la baja producción azucarera los hay de carácter objetivo y subjetivo. Se encuentran problemas en la siembra que origina la pérdida de muchas cepas. Por otra parte hay centrales azucareras que tienen deficiencias de producción por su mala maquinaria y la falta de repuestos. Hay algunos que tienen que parar la producción y enviar la caña a otras centrales. También hay problemas de carácter subjetivo. En el Informe Central se crítica el poco espíritu de trabajo y se pide a los cuadros del Partido una intensificación de su actividad. "Esta trabajo se viene haciendo hoy prácticamente por todos los organismos, aplicando principios de administración, de contabilidad; es una actividad que hay que intensificar. Es una lucha dura para evitar los criterios subjetivos, los amiguismos, la indolencia, la tolerancia, que lo vemos y que sabemos que hay en muchas partes" ${ }^{23}$.

Pero algunas producciones sí han experimentado crecimiento: el petróleo y el gas mejoraron en su producción debido al avance de las prospecciones, lo mismo que el cemento, los materiales de construcción y la producción de electricidad, las producciones tabacaleras y la generación de energía eléctrica. Algunos de estos productos han comenzado a crecer como consecuencia de la preocupación interior a medida que desaparecieron los suministros procedentes del bloque socialista.

La producción de níquel ha constituido uno de los principales empeños del Gobierno cubano en vista de las grandes potencialidades de Cuba que se situaría en el segundo productor de níquel en el mundo después de Canadá. En el año 1997 se calcula que esta producción superaría las 25.000 toneladas, y es posible que en el 1998 aumente.
En la pesca se han producido también resultados importantes, especialmente en la pesca de langosta que se ha convertido en un producto de exportación. Crecieron los cultivos en presas, lagunas y estanques para paliar las dificultades de la pesca marítima por falta de combustible. También creció la producción de arroz.

El turismo ha pasado de 267 millones de dólares en 1991, con motivo del IV Congreso, hasta los 1.380 millones de dólares en 1996. Se reconoce la gran aportación que ha realizado en este sector la empresa mixta, donde el capital extranjero juega un papel decisivo. El turismo está proporcionando las divisas que el país necesita para la obtención de materias primas.

Como consecuencia de las imposiciones del bloqueo norteamericano, la industria farmacéutica cubana ha tenido que desarrollar nuevos productos y aproximadamente son unos 700 productos los que se elaboran en el país. También la biotecnología ha obtenido un gran desarrollo para encontrar nuevas posibilidades en el sector farmacéutico.

El salario medio cubano es muy bajo, pero en el Informe Central se considera un triunfo al haber pasado de 182 pesos a $208^{24}$. Todavía contrasta más esta situación salarial en su comparación con el área del dólar que permite adquirir productos en mercados especiales. La divisa americana ha oscilado mucho y ha bajado mucho su cotización, pasando a cambiarse en el mercado interior de 150 pesos por dólar hasta 23 pesos por dólar.

\section{LOS PROBLEMAS DEL DESARROLLO}

La concepción de desarrollo por parte de la Revolución cubana está relacionada con la toma de conciencia de los problemas. El modelo de desarrollo cubano se centra en la primacía del modelo socialista sobre el capitalista no aceptando la imposición de criterios de desarrollo parecidos a los que impone la política norteamericana o los organismos internacionales como el Fondo Monetario Internacional o el Banco Mundial. No acepta tampoco imposiciones que vengan de fuera condicionadas por el proceso de globalización. Se trata de ser conscientes de los problemas que hay y la forma de resolverlos; cuales son las carencias y cuales son los avances que se van produciendo. Cuales son las condiciones de vida y las circunstancia que permiten un mayor bienestar. En el Informe Central se destacan las cifras que han hecho de Cuba un país que puede ofrecer tasas muy bajas de mortalidad infantil $\left(7,4\right.$ por mil) y una esperanza de vida de 76 años ${ }^{25}$.

Hay una gran escasez de alimentos y una productividad muy baja, pero son elevados los índices de alfabetización y un destacado puesto en desarrollo cultural y deportivo. Fidel Castro hace una comparación con otros países del Tercer Mundo y destaca la diferencia con los datos que puede proporcionar Cuba en materia de educa-

22. Ibid. Pág. 8.
23. Ibid. Pág. 7.
24. Ibid.
25. Ibid. Pág. 8. 
ción, sanidad, asistencia social, deporte, etc. Cree que hay muchos otros países que viven también en "un período especial”. Incluso algunas de las cifras que ofrece Cuba en material educativa y sanitaria pueden superar los índices de los países desarrollados.

Como corresponde a toda economía socialista, los salarios se garantizan a todos los trabajadores; "salario modesto, pero salario, para adquirir aquellas cosas que pueden adquirir con el salario" ${ }^{26}$. Se atiende a los jubilados en su totalidad. Hay 1.400 .000 personas protegidas por la jubilación. Hay una lucha también contra enfermedades nuevas como el SIDA. Cuba está trabajando en una vacuna contra el SIDA. Y, aunque de una forma aislada, Cuba pretende sacar adelante el desarrollo del país anteponiendo su dignidad a las imposiciones exteriores. Esta es la lucha peligrosa frente a un mundo que cada vez es más interdependiente y donde no puede quedarse nadie aislado. Algunas concesiones, no obstante, pueden darse, y de hecho se están produciendo, en el plano económico; lo que tarde o temprano tendrá que convertirse en concesiones políticas.

\section{LA CRÍTICA AL CAPITALISMO}

Fidel Castro hace una permanente crítica al capitalismo y por todos los medios no quiere que se introduzcan las prácticas que puedan contaminar el socialismo y la hegemonía del Partido Comunista. Las concesiones que se han hecho en materia de organización económica se consideran como una necesidad coyuntural para mejorar la acción revolucionaria. "Yo pienso que no estamos equivocados" 27 , dice. Cree que el capitalismo pertenece a la prehistoria, siguiendo las enseñanzas de Carlos Marx al situar el final de la prehistoria del hombre en el momento de su acceso al socialismo. Se trata especialmente de una crítica al capitalismo a raíz de la consideración de una falta de humanismo; " no tiene nada que ofrecer al hombre: un lobo queriendo devorar a otro lobo, esa es su prédica; un egoísmo despiadado que no tiene nada que ver con lo que deseamos para el ser humano" ${ }^{28}$.

Se hace una comparación de lo que ha ocurrido con los países del antiguo mundo socialista en donde se supone que se ha producido un desastre económico y social: corrupción, robo, desempleo, desigualdades, pobreza, emigración. Fidel Castro destaca las desigualdades que produce el capitalismo y como se toleran y fomentan esas desigualdades, lamentándose de la actitud y comportamiento que se tiene con Cuba por practicar una política distinta. Afirma irónicamente que "hay que castigar la honradez, hay que castigar la justicia, hay que castigar los verdaderos derechos humanos, hay que castigar la verdadera democracia, hay que castigar todo lo que no sea capitalista o imperialista" ${ }^{29}$.

En el discurso de clausura Fidel Castro insistiría en sus críticas al capitalismo al que considera explotador y provocador de injusticias. El capitalismo, además, dice, "conduce al mundo hacia el abismo de la contaminación, que puede hacer irrespirable el aire, que puede envenenar los ríos y los mares; muchos están en parte envenenados y dejan de ser fuentes de alimento, fuentes de salud" ${ }^{30}$. No obstante, no duda de la eficacia de la empresa capitalista, como puede comprobarse en los pequeños negocios de comida que se han establecido en Cuba. En su interpretación esto ocurre porque el capitalismo administra bien. Esto es lo que quiere copiar del mundo capitalista, la forma de administrar y la eficacia. Esto se propone como modelo para la empresa socialista, porque, "si el capitalista puede, nosotros podemos más que el capitalista”, dice enfáticamente.

\section{LAS ORGANIZACIONES DE MASAS}

Para la Revolución cubana las organizaciones de masas son la verdadera correa de transmisión del Partido que llega hasta los sectores más recónditos de la sociedad cubana. Son la verdadera red articulada que pone en práctica las directrices del partido y los lineamientos para la acción más eficaz. En el Informe Central se destaca esta importancia y se señala que "el Partido y las organizaciones de masas forman un conjunto sin el cual sería imposible la Revolución" " ${ }^{31}$. Es alabado fervientemente en el Informe Central el trabajo que vienen llevando los Comités de Defensa de la Revolución ${ }^{32}$, la Federación de Mujeres Cubanas, los campesinos, los estudiantes, los pioneros (niños organizados en una formación paramilitar), las nuevas organizaciones como la Asociación de Combatientes de la Revolución Cubana, así como el papel que juega la Central de Trabajadores Cubanos y las Unidades Básicas de Producción Cooperativa. Todas estas organizaciones de masas han ido surgiendo, especialmente en los primeros años de la Revolución, para defensa de la misma y en una alianza directa con el Partido.

En el Congreso del Partido no puede faltar una alusión directa a los que son verdadero semillero del mismo y por eso se hace una referencia a la juventud cubana que sigue siendo entusiasta al lado del Partido, la Unión de Jóvenes Comunistas. Se recuerdan sus actividades con motivo del festival internacional de la juventud del año 1994, y la prestación del trabajo que requiere el período especial. Después del IV Congreso se consideró que la juventud no era especialmente favorable a su inserción en el Partido por indiferencia política. En el Informe Central se dijo que sólo la mitad de los que ingresan en el Partido proceden de las filas de la Unión de Jóvenes Comunistas; "es necesario trabajar más fuerte en nuestras filas juveniles” ${ }^{33}$, decía Fidel Castro.

26. Ibid

27. Ibid. Pág. 9

28. Ibid

29. Ibid. Pág. 10

30. Granma, Discurso de Clausura (Suplemento). La Habana, 1-XI97. Pág. 2

31. Granma, Informe Central. La Habana, 29-X-97. Pág. 10.

32. Los CDR son una organización que tiene oficinas en todas las manzanas del ámbito rural y en cada núcleo rural de 200 habitantes. Desempeña importantes funciones de control e información, así como actuaciones en la distribución de alimentos y registro de población. Cuenta con unos 6 millones de miembros.

33. Granma, Informe Central. La Habana 29.X-97. Pág. 10. 


\section{LA LUCHA IDEOLÓGICA}

Para Fidel Castro la defensa de la Revolución pasa por la defensa de las conquistas sociales y las conquistas de los trabajadores. En el Informe Central se resalta la corriente contemporánea contraria a la intervención del Estado y a todo lo que supone la preponderancia del sector público sobre el privado. Cree entrever en todo esto una gran campaña de los medios de comunicación en todo el mundo propiciada por la desaparición del campo socialista en contra del papel del Estado y forzarle a ser el represor de las protestas de los trabajadores. Se aludió especialmente a las emisoras contrarias a la Revolución que son partidarias del liberalismo y la globalización, ofreciendo al mundo un modelo de sociedad consumista que introducen conceptos de desarrollo al estilo norteamericano, "el cual no es modelo para nadie".

Como contrapunto señala la situación en que se encuentran los países del sudeste asiático en su gran crisis económica, que de ser el modelo del desarrollo capitalista "de repente caen en las redes de los especuladores que hacen negocios turbios, que arruinan a estos países ${ }^{34} \ldots$ manipulan y reducen el valor de las acciones en las bolsas, manipulando y reduciendo el valor de las monedas, sin que puedan hacer nada".

En un comentario a la resolución económica escrito en Granma por la periodista Susana Lee se destacan los "problemas ideológicos" serios que crean las desigualdades derivadas del afán desmedido de poseer divisas como consecuencia de la despenalización del dólar y el trabajo por cuenta propia ${ }^{35}$. Son los vicios capitalistas que se rechazan como inspiradores de las desviaciones ideológicas. Fidel Castro establece una comparación entre los valores socialistas y los que ofrece la propaganda capitalista; mientras el socialismo trabaja por el desarrollo de los pueblos, el capitalismo ofrece el modelo consumista. "No es la economía al servicio de hombre, de la sociedad, de su bienestar, de su salud, su salud física y su salud moral, de su seguridad. Lo aplican y educan a los pueblos en la idea del despilfarro y de los gastos desenfrenados que la naturaleza no puede ya soportar" ${ }^{36}$.

También se percibe un duro debate ideológico entre los diversos modelos de desarrollo que se producen en el mundo afectados por el proceso de globalización, y los líderes e ideólogos del proceso revolucionario cubano, especialmente los más jóvenes. No está ausente de este debate, que se ha producido con motivo del V Congreso y seguirá condicionando las relaciones interiores y exteriores. También el modelo de democracia está en el debate interno y se escriben ya artículos de opinión en los periódicos en torno al tema de la "democracia" ${ }^{37}$ con el propósito de argumentar a favor de la practicada en Cuba desde la implantación del Poder Popular en 1976, pero se contrasta con la practicada en los países donde hay pluralidad de partidos. Incluso se comenta la transición a la democracia en los países del antiguo campo socialista.

Al aprobar la Resolución sobre el Partido se especificaba que dicho documento debía ser "parte esencial de la plataforma ideológica y política del Partido" ${ }^{38}$. De dicho documento habrán de extraerse los programas de formación política que constituyan la argumentación dogmática que se aplicará en los fundamentos teóricos de los comités y asambleas del Poder Popular, para garantizar la continuidad.

\section{LA RESOLUCIÓN SOBRE LA UNIDAD DEL PARTIDO}

En todos los Congresos del PCC se presentan resoluciones que previamente han sido puestas en conocimiento de los militantes para su estudio y posibles propuestas ${ }^{39}$. Contrasta la diferencia, no obstante, entre otros Congresos y éste al momento de presentación de resoluciones. En todos se habían presentado más que en éste. Pero si aquí se han presentado menos la referente al Partido se ha considerado sustancial, también lo ha sido, ciertamente, la resolución sobre la situación económica. Ambos son aspectos claves en la vida política y económica del país pues de ello depende la evolución de la sociedad cubana, las relaciones internacionales y el futuro del desarrollo económico y social.

La resolución sobre el Partido, presentada por Raúl Castro, y con el título "El Partido de la unidad, la democracia y los derechos humanos que defendemos" ${ }^{40}$, proporciona en el título tres conceptos susceptibles de profunda consideración y debate interno y externo. Se hace alusión a la unidad, la democracia y los derechos humanos. De sobra es conocido que la unidad entendida como defensa de la existencia de un solo partido representa uno de los grandes problemas para la aceptación desde el exterior de las facilidades de crédito y cooperación. De la misma manera que el concepto de democracia que se define desde la ideología del PCC no es homologable con la aceptada y practicada en los países de práctica pluripartidista. Lo mismo puede decirse del tratamiento de los derechos humanos que siempre resulta discrepante entre los regímenes autoritarios y las democracias occidentales.

34. Ibid. Pág. 13

35. Lee, Susana: "Sobre la resolución económica", en Granma. La Habana, 7-X-97. Pág. 3.

36. Granma, Informe Central. La Habana, 29-X-97. Pág. 13.

37. Ver los artículos de Ernesto Montero Acuña sobre "La democracia limitada”, en Trabajadores. La Habana, 20-X-1997. Pág. 7; de Martina Menéndez sobre "La democracia no es sólo una forma de Gobierno", en Juventud Rebelde. La Habana, 2-XI-1997, Pág. 6; y de Lázaro Barredo Medina sobre "El drama de la "democracia", en Trabajadores La Habana, 3-XI-97. Pág. 6.

38. "La unidad es el arma indestructible del pueblo", en Granma, La Habana, 9-X-1997. Pág. 6.

39. Según una información digital proporcionada por CubaNet, octubre 97, a esta resolución sobre el Partido se presentaron 20.000 sugerencias de modificaciones. Esta cifra se considera escasa si se compara con la similar del IV Congreso para la que se informó que se habían presentado millones de opiniones de la población. http://ella.netpoint.net/cubanet/Cnews/y97/oct97/01a3.htm

40. La propaganda oficial hace referencia a que este documento ha sido apoyado por seis millones y medio de cubanos mayores de 14 años, en un país de 11 millones de habitantes. Ver Información del Departamento de Rel. Inter. del Comité Central en http://www2.ceniai. inf.cu/pcc/congreso_html 
En la resolución se hace una descripción histórica de la trayectoria seguida por Cuba hacia la independencia y hacia el triunfo y consolidación de la Revolución. Se hace alusión a las luchas llevadas a cabo por los cubanos para conseguir su libertad e independencia frente a colonizadores de distinto tipo, reforzando las ideas de José Martí que creó un partido, el Partido Revolucionario, como defensor de la existencia de un solo partido ${ }^{41}$. La lucha revolucionaria habría sido una, la única, desde que se consiguió la independencia hasta el presente.

Muy diferente es la visión que tienen los más de un millón y medio de cubanos que presencian la evolución de su país desde el exilio y que consideran mas bien la realidad de la desunión de los cubanos. En un documento digital que se publica con el título "La Patria es de Todos", un grupo de cubanos en el exilio rechaza el argumento de la "unidad de partido" en que se pretende demostrar que todo el pueblo cubano está con el PCC. Para esto, "es necesario que surja el consenso libremente alcanzado por los ciudadanos...; la unidad a la que se refiere el Partido no es de ideas, sino la pretensión de que la población esté alrededor de una cúpula dirigente" ${ }^{42}$.

Los militantes del Partido Comunista de Cuba se cifran en 770.000 miembros, a los que hay que añadir el número de miembros que pertenece a la Unión de Jóvenes Comunistas que está en torno a los 500.000. Bien sabido es que no llegan a la mitad los miembros de la UJC que ingresan en el PCC. De una manera destacada se resalta en la Resolución que en los últimos cinco años han ingresado en el PCC 232.000 trabajadores ejemplares... el 30\% de la actual militancia" ${ }^{43}$.

Lo manifestado en la Resolución sobre el Partido se complementa con una reafirmación hecha en la Resolución sobre la revisión de los estatutos donde se reconoce la existencia en Cuba de un solo Partido Martiano y MarxistaLeninista ${ }^{44}$ con garantía de la unidad y cohesión del pueblo. Esta revisión de Estatutos del Partido, en realidad, no ha servido para presentar ningún signo de cambio ni en los principios ni en la estructuración democrática.

Se especifica en la Resolución la necesidad de promover nuevos cuadros y la necesidad de corregir las insuficiencias y errores individuales o generales. Por una parte se observa que el PCC envejece muy rápidamente ${ }^{45}$ y no resulta extraño encontrar escándalos tan notables como los que dieron origen a la expulsión del partido de Carlos Aldana, que a la sazón era el ideólogo de Partido. Quizás la renovación generacional pudiera contribuir en el futuro a una mayor apertura hacia formas democráticas más parecidas a los países democráticos con pluralidad de partidos. De momento en el $\mathrm{V}$ Congreso no se ha avanzado en esa dirección.

\section{LA DEMOCRACIA Y LOS DERECHOS HUMANOS}

La democracia que se defiende en el documento se vincula directamente a la actuación de las organizaciones de masas ${ }^{46}$, que han cumplido funciones de comunicación, debate, movilizaciones, pero que dista mucho de ser representativas, y menos aún sometidas a proceso electoral alguno. Se quiere demostrar que las organizaciones de masas, las agrupaciones sociales y profesionales y otras formas de asociación han dado espacio a los intereses y las preocupaciones de todos los sectores de la sociedad civil. Esto tampoco puede corroborarse en lo concerniente a las inquietudes y manifestaciones políticas. De las libertades políticas no se habla en el documento del Congreso porque la actividad política corresponde únicamente al PCC.

En el IV Congreso se introdujo la elección directa y secreta de los diputados a la Asamblea Nacional y a las Asambleas Provinciales, y si bien éstos tienen que rendir cuentas periódicamente a sus electores y pueden ser revocados en cualquier momento, no está clara la representatividad de los mismos y menos aún representan la propuesta de un programa alternativo. En el V Congreso se reitera que "los candidatos son propuestos y seleccionados en reuniones de vecinos; la votación es libre, secreta, directa y el escrutinio, público; para ser elegidos es necesario alcanzar más del $50 \%$ de los votos", pero no se abre ninguna alternativa a formas de oposición y mecanismos viables que conduzcan a la cúspide del poder o pueda existir alguna dirección que no pertenezca al PCC.

En el V Congreso se sigue propagando la idea de la perfección del sistema democrático cubano y en el Resolución sobre la revisión de los Estatutos se sigue señalando la vigencia de los principios del "centralismo democrático" como la piedra angular de la estructura y funcionamiento de la organización y la dirección colegiada. En este punto no hay ningún cambio desde el I Congreso de 1975.

Aunque en el título de la Resolución se hace alusión a los "derechos humanos que defendemos", realmente no se suscita el tema y ni siquiera se mencionan libertades específicas que tengan cabida en un código de derechos sociales o económicos, por no hacer referencia a los derechos políticos.

41. Granma Internacional. Edición Digital. La Habana 1997 Palabras de José Martí sobre el partido: "Nació uno, de todas partes a la vez, y erraría, de afuera o de adentro, quien lo creyese extinguible o deleznable. Lo que un grupo ambiciona, cae. Perdura, lo que un pueblo quiere. El Partido Revolucionario Cubano es el pueblo cubano”. Pág. 12.

42. El manifiesto "La Patria es de Todos" ha sido difundido por internet ...XITO Home Page. News and Politics. http://192.191.98/091 ht Pág. 2 y 3 . Fue elaborado por opositores al régimen cubano y que pasaron algún tiempo en las cárceles cubanas: Félix Borne Carcasses, René Gómez Manzano, Vladimiro Roca Antúnez y Martha Beatriz Roque Cabello.

43. Granma: Informe Central. La Habana, 29-X-97. Pág. 11.

44. Esta misma declaración de un Partido Marxista-Leninista se encuentra en la Constitución de 1992, Art. 5, por lo que cualquier cambio fundamental en la evolución de la Revolución Cubana hacia una democratización homologable por las democracias occidentales debería pasar por un cambio de la Constitución. La alusión al Partido Martiano tiene un sentido más nacionalista que no significa más que una concesión al patrio tismo cubano que no encuentra relación entre el pensamiento de Martí y la concepción marxista-leninista de la sociedad, el Estado y la política.

45. En el Comité Central del V Congreso quedaron fuera del mismo dos de los "históricos" de partido, Carlos Rafael Rodríguez y Osmany Cienfuegos. Carlos Rafael Rodríguez, uno de los grandes intelectuales e ideólogos del PCC falleció posteriormente a una avanzada edad.

46. Las organizaciones a que se hace referencia son la Central de Trabajadores Cubanos, la Asociación Nacional de Agricultores Pequeños, los Comités de Defensa de la Revolución, la Federación de Mujeres Cubanas, las organizaciones estudiantiles, la Asociación de Combatientes de la Revolución Cubana y otras de carácter social. 


\section{LA RESOLUCIÓN ECONÓMICA}

La Resolución económica planteó los serios trastornos que sufre la economía cubana desde que se produjo la desaparición del bloque socialista y la desintegración de la Unión Soviética. La pérdida de un $75 \%$ del mercado (en el IV Congreso se había dicho un $85 \%$ ) influyó de una manera decisiva en las previsiones que se habían formulado con motivo de IV Congreso. En el anterior Congreso se habían formulado unos criterios que volverán a plantearse en el V Congreso: producir alimentos básicos, introducir adelantos de la ciencia y la técnica, ampliar el plan de inversiones, organización y remuneración más eficaces, atención al hombre y movilización de recursos humanos. Esos criterios, después de seis años, tienen que volverse a plantear textualmente.

Entre los dos últimos Congresos, ciertamente, se han producido algunos hechos que esta Resolución destaca de manera especial para situar en su justo punto las grandes deficiencias por las que pasa la economía cubana y que provienen de causas externas. La aplicación de la Ley Torricelli en 1992, y la posterior Ley Helms-Burton de 1996 han acentuado el embargo norteamericano de tal manera que el efecto se ha notado. Sin entrar en valoraciones, por mi parte, de la conveniencia o no de estas medidas, el argumento de bloqueo es una razón muy poderosa para que las autoridades cubanas culpen a esta medida de todos los males económicos, como primer argumento, y menos a la eficacia o no del sistema en sí mismo.

Como consecuencia de la difícil situación económica a principios de los años 90 se declaró el "período especial" urgiendo a los cubanos a intensificar la aplicación al trabajo y la consecución de más eficacia y resultados positivos en el mismo. Los renglones más afectados por la crisis han sido la alimentación, los medicamentos, la energía, el transporte y otros servicios públicos. Pero el descenso más acusado ha sido el de la producción azucarera. A todos ello contribuyen las causas apuntadas, pero también los propios errores. En el Informe Central se critica la poca eficacia de las unidades básicas de producción cooperativa (UBPC) para resolver los problemas para los que fueron creadas: aumentar la producción azucarera y mejorar el sector alimenticio. Su creación se presentaba como una alternativa competitiva frente al mercado libre campesino, pero no han alcanzado los resultados esperados.

\section{MEDIDAS ECONÓMICAS PLANTEADAS EN EL V CONGRESO}

La medida aplicada después de la celebración del IV Congreso, la creación y puesta en marcha de las UBPC, se considera que tiene que ofrecer resultados positivos. El congreso reconoce que "hasta el presente, en la mayoría de las casi 4.000 unidades de este tipo, en particular las cañeras, no se ha alcanzado los resultados que se espera de ellas por lo que será imprescindible corregir las desviaciones en su funcionamiento ${ }^{47}$. En unas informaciones repartidas por la agencia de noticias cubana, Prensa Latina, se ponía de manifiesto que el $70 \%$ de estas cooperativas no eran rentables $^{48}$. Entre las causas que se apuntaban estaba la inexperiencia de los trabajadores en el ejercicio de su autonomía o por resistencia del aparato estatal a ceder control. La realidad demanda mayor eficacia y se considera necesario la actuación sobre la reducción de costes, la mejor utilización de tecnología, mejorar la disciplina laboral, mejorar la medición y la contabilidad, mejorar la organización del trabajo y mayor implicación de los cuadros del Partido ${ }^{49}$. La aplicación de 19 medidas para el fortalecimiento de las UBPC se considera que contribuirán a la mayor aportación de productos alimenticios.

Para completar esta medidas de eficacia se introducen incentivos específicos "sobre bases de estricta eficiencia económica” y sin acudir a subsidios injustificados. Se introduce una política fiscal "que propicie la generalización de la política tributaria, como vía de una justa redistribución de los ingresos y contribuir al sostenimiento de los gastos sociales" ${ }^{50}$. Esto tiene especial dedicación a las nuevas experiencias admitidas en la economía cubana, como son las empresas mixtas, la inversión extranjera, el trabajo por cuenta propia y la despenalización del dólar. A esto se le llama con la pomposa denominación de "mecanismos de mercado bajo regulación estatal" ${ }^{51}$.

Según observaciones realizadas por sectores de la oposición, las actividades por cuenta propia que se han iniciado en Cuba experimentan una mayor eficacia que las actividades paralelas des sector público oficial. "Los 'cuentapropistas', a los que el sistema ha tratado de ahogar por lo que representa desde el punto de vista político, convierten en un derroche de eficacia cualquier pequeño negocio que emprenden... Si verdaderamente se quiere estimular la creatividad de las masas en todas las esferas, hay que permitir ésta en el terreno económico, no impidiendo que el cubano pueda invertir, tal y como se autoriza al extranjero" ${ }^{52}$.

La introducción de nuevas experiencias de producción o mercado que han sido copiadas de la experiencia capitalista se le dedica una regulación especial. Es la necesidad lo que produce esta aceptación no querida y por eso el Congreso, en su Resolución económica, expresa que "corresponde al Estado Socialista corregir las distorsiones inherentes a los mecanismos de mercado a fin de disminuir sus efectos negativos y, sobre todo, tomar en cuenta que su inevitable presencia supone retos y peligros que es indispensable enfrentar en lo económico, político, ideológico y social" " 33 . Las suspicacias y salvaguardas que se ven diseminadas en los mensajes de Congreso y en los discursos de

47. Granma, Resolución Económica del V Congreso del Partido Comunista. La Habana, 7-XI-97. Pág. 1.

48. CubaNet ttp://ella.netpoint.net/cubanet/Cnwe/y97/oct97/. 082htm. Pág. 2

49. Granma: Informe Central. La Habana, 29-X-97. Pág. 11.

50. Ibid. Pág. 3.

51. Ibid.

52. "La Patria es de Todos", EXITO Home Page. News and Politics. Pág. 5.

53. Granma: Resolución Económica del V Congreso del Partido Comunista Cubano. La Habana, 7-XI-97. Pág. 3. 
inauguración y clausura manifiestas su discrepancias con estas prácticas copiadas del capitalismo.

\section{PERSPECTIVAS DE LA ECONOMÍA CUBANA}

A pesar de las dificultades experimentadas en los últimos años cuando el PIB llegó a caer hasta el 38\% entre 1990 y 1993 puede esperarse una recuperación de la economía. Habiendo crecido el PIB en los años siguientes un $0.7 \%$ en 1994 , un $2,5 \%$ en 1995 y un $7.8 \%$ en 1996 , se prevé que la economía cubana pueda situarse en los próximo años entre el $4 \%$ y $6 \%$ de promedio anual. Las previsiones para 1997 eran de un crecimiento de un $4 \%$, pero el ministerio de economía cubano admitía la dificultad para conseguirlo debido a la baja zafra azucarera ${ }^{54}$, los bajos precios internacionales del azúcar y el níquel, así como el incremento de los costes del petróleo y el paso de huracán "Lily" que había causado grandes estragos". En unas declaraciones del Ministro de Economía a la agencia EFE en vísperas del Congreso se mostraba cauto en los cambios y decía que "para avanzar en las reformas hay que consolidar lo que ya se ha hecho... Nuestro modelo sigue siendo el socialista y el papel protagonista en la economía corresponde al Estado, que es el que debe concretar los recursos para impulsar producciones claves como el níquel, el turismo o la biotecnología" 56 .

A los problemas históricos del embargo norteamericano hay que añadir los que se derivan de la carga que supone una deuda exterior de más de 10.000 millones de dólares, lo que le convierte en un país que sólo recibe créditos a corto plazo y elevados intereses del 14 y 15 por ciento, la escasez de divisas ${ }^{57}$, y el no pertenecer a ningún organismo financiero internacional.

Las mejores perspectivas de desarrollo se pueden producir en el sector del turismo debido a que Cuba cuenta con grandes recursos naturales, paisaje, clima, playas y un desarrollo cultural que permite ofrecer grandes atractivos al turismo procedente de los países latinos y de los Estados Unidos. Este es el mercado turístico que puede abrir un cambio económico e ideológico que suponga de gran desarrollo de Cuba, sin bien los factores ideológicos son los que más preocupan al Gobierno de Cuba para favorecer la apertura al gran turismo. Carlos Lage, considerado el número tres en la escala de poder en Cuba, y que es Vicepresidente encargado de los asuntos económicos, ya vaticinó que la economía no crecerá al ritmo que se había pronosticado.

No se prevén cambios en la introducción de pequeñas y medianas empresas que pudieran actuar de forma privada. Todas las que hay actualmente en Cuba son estatales o de capital mixto. En opinión de Carlos Lage, más bien se potenciará la mediana y pequeña empresa estatal ${ }^{58}$. El sector privado está integrado principalmente por campesinos que poseen en torno al $15 \%$ de la tierra cultivable, y hay uno 170.000 trabajadores por cuenta propia que se concentran sobre todo en el sector de la gastronomía. Todos los avances de privatización son difíciles mientras en Cuba no se perfeccionen los mecanismos tributarios. Después de casi cuarenta años sin un sistema fiscal adecuado y sin tradición actualizada del mismo no resulta fácil introducir estas medidas en una economía dominada básicamente por la empresa estatal y un centralismo planificador como el que existe.

\section{LA CLAUSURA DEL CONGRESO}

En la clausura del Congreso Fidel Castro realizó un amplio resumen que sintetiza la esencia principal de los documentos presentados y las resoluciones aprobadas. Es importante destacar la reafirmación en los valores del socialismo y la crítica constante el sistema capitalista sin aceptar nada positivo. Decidido a hacer una comparación con los sistemas y experiencias alternativas de mercado solamente admite alguna experiencia provisionalmente. "Nosotros, dice, no podemos entregar nuestro desarrollo económico y social a las leyes ciegas del mercado. Las leyes ciegas del mercado no imperarán aquí, eso no quiere decir que no podamos aplicar alguna forma de mercado" ${ }^{59}$. Ni siquiera se inclina por el ejemplo chino, que aplica una economía de mercado socialista. Castro dice que observa los que hacen, pero destaca que hay programas, panes, un Partido y están buscando qué mecanismos capitalistas pueden serles de alguna utilidad. Defiende el papel hegemónico del Estado como determinante y fundamental. En todo caso, considera que las condiciones de los chinos son muy diferentes a las de Cuba y no es posible introducir ningún sistema de privatizaciones.

Quiere Fidel Castro que haya una revitalización en los valores del hombre socialista y propone el modelo que practican las religiones. Compara dramáticamente el tipo de hombre que produce el capitalismo, que "produce bestias", con el sistema socialista que produce hombres. El socialismo no lo hace por sentimientos religiosos, "pero para nosotros la justicia es una religión; para nosotros la libertad, el bienestar de nuestros compatriotas es una religión, la independencia es una religión, la patria es religión. Es decir, todo: revolución, patria, independencia, justicia social, el socialismo, es para nosotros como una religión" ${ }^{60}$.

54. En un congreso de técnicos azucareros celebrado en La Habana en noviembre de 1997 se señalaba que, por diferentes razones, un 30\% del área sembrada de caña carece de cepas y ese mal es una de las causas de los bajos rendimientos agrícolas. Uno de los técnicos participante en el congreso aseguraba que había mucha indisciplina técnica y chapucería en la producción azucarera, a pesar de la gran inversión que se hacía, en torno a los 150 millones de dólares. Para salvar el proceso productivo se nombró en su día al General de División Ulises Rosales del Toro como Ministro del Azúcar. Este General advirtió en el congreso sobre la "urgencia de transformar cuanto antes el panorama cañero y dar saltos firmes hacia una etapa superior"- Ver Granma, La Habana, 13-XI-1997.

55. ABC, "Hoy arranca otro congreso del Partido Comunista de Cuba con freno y marcha atrás. Madrid, 8 de octubre de 1997. htm.

56. CubaNet News-EFE: http://ella.netpoint.net/cubanet/Cnews.

57. Según datos de la CEPAL las remesas familiares de dólares ascienden a 800 millones, lo cual supera los beneficios generados por la industria turística y azucarera.

58. Declaraciones de Carlos Lage en un hotel de Varadero y recogi das por CubaNet-EFE, Octubre 1997.

59. Granma, Discurso de Clausura. (Suplemento) La Habana, 1-XI1997. Pág. 4.

60. Ibid. Pág. 6. 
Quisiera equiparar el espíritu de los revolucionarios al de los misioneros.

De importante ha sido destacada la alusión hecha por Fidel Castro a su hermano Raúl como su posible sucesor: "cuiden a Raúl más que a mí, porque a Raúl le queda más juventud, más energías que a mí... espero que ustedes puedan contar con él mucho más tiempo" ", en clara insinuación a su deseo de que pueda ser Raúl quien le sustituya al frente del Partido y del Gobierno. En algunos de los sectores más jóvenes del Comité Central esta alusión ha causado cierta decepción al enfrentarse esta realidad, ya que "ni con los fieles ni sin ellos, se realizarán cambios en Cuba, mientras esté Fidel Castro en el poder" ${ }^{62}$.

\section{BALANCE DEL CONGRESO}

Si se analizan los resultados del V Congreso por las palabras de Fidel Castro, éste ha sido el mejor Congreso de todos los realizados debido a las grandes confirmaciones. "De este Congreso puedo decir que salgo con más seguridad que nunca de que estamos siguiendo el camino correcto... con más convicciones que nunca, con más seguridad que nunca... de que nuestro pueblo conquistará un lugar importante en la historia" " ${ }^{3}$. El lenguaje utilizado simula el propio de las Iglesias que tienen perdurabilidad, pero con la diferencia de que el Partido no es una Iglesia y el comunismo no es una religión.

Con anterioridad a la celebración del Congreso, Esteban Lazo, que es miembro del Buró Político del Partido y Primer Secretario del Partido en La Habana, ya hacía un balance positivo del Congreso: "Bastaría echarle un vistazo a lo que está pasando en el mundo, el saldo de la globalización, del neoliberalismo, como aumenta la pobreza, el desempleo, la mortalidad, los niños desamparados, y compararlo con nuestro país que después de 5 ó 6 años, aunque con dificultades, hemos logrado mantener la salud de nuestro pueblo, la educación, no haber afectado a nadie en la seguridad social, no dejarle a nadie desvalido" ${ }^{64}$. No se había comenzado el Congreso y los líderes del Partido ya estaban seguros de que no había otra alternativa más que seguir por el mismo camino porque la oposición, u otro camino recomendado, no era correcto.

Una de las primeras medidas del Consejo de Estado al terminar el Congreso era convocar elecciones para un término de cinco años, a partir del enero de 1998, para que los delegados elegidos para las Asambleas Provinciales y los Diputados a la Asamblea Nacional pongan en práctica las conclusiones del Congreso, de acuerdo con las resoluciones aprobadas ${ }^{65}$. De acuerdo con estas intenciones los cambios en las orientaciones políticas no existen y en los planteamientos económicos se mantienen en una continuidad de lo que se estaba haciendo hasta ahora. La experiencia enseña, no obstante, que cualquier nueva medida puede tomarse por parte de la Asamblea Nacional o el Consejo de Estado con independencia que lo que se haya resuelto en el Congreso del Partido.

En una noticia que ofrecida el periódico oficial Granma el 30 de octubre de 1997, se daba cuenta de una disposición del Ministerio de Educación cubana según la cual las resoluciones y otros documentos del V Congreso pasarían a forma parte de los textos que deberían estudiar los escolares en Cuba, desde el nivel infantil al universitario. Algunos delegados al Congreso ya habían solicitado que la Resolución sobre el Partido se constituyera en texto de estudio obligatorio para todos los niveles de la educación. Alguno, incluso, manifestó que debería ser libro de consulta familiar. En palabras del titular de dicho Ministerio, Luis I. Gómez, "estos materiales habrán de convertirse en textos de todo el sistema educacional, adecuados a los distintos grados y niveles" " ${ }^{6}$. A este propósito fueron reunidos todos los directores municipales y provinciales de educación del país para coordinar esta iniciativa ${ }^{67}$. En dicha reunión el miembro del Buró Político, José Ramón Balaguer, subrayó que debían tenerse en cuenta, como elementos de conducta y actitud ética, los principios de independencia, justicia social y eficacia que habían sido aprobados por el Congreso. De esta manera el V Congreso se convierte en un paso más en la misma dirección y por la vía estrecha, o, según un titular de El País, "los comunistas cubanos ratifican el socialismo y la reforma 'lenta' con vistas al siglo XXI" ${ }^{68}$.

61. Ibid. Pág. 7.

62. "Actualidad Cubana", en Noticias de Cuba: http://www.canfinet.org/spanish/press/c971103a.htm.

63. Granma, Discurso de Clausura. La Habana, 1-IX-97. Pág. 8.

64. Lee, Susana: Entrevista a Esteban Lazo "Va a ser un Congreso de altura de lo que se necesita en estos momentos”. En Granma, La Habana, 7-X-97. Pág. 4.

65. La primera vuelta de las elecciones para delegados del Poder Popular Municipal se inició el 19 de octubre de 1997 (la novena convocatoria en toda la historia del Poder Popular cubano) con un registro de ciudadanos aptos para ejercer el sufragio de 7.828 .439 electores, según confirmaciones de la Comisión Electoral Nacional. Las elecciones se celebraron ese domingo en 32.337 colegios electorales de las 14.533 circunscripciones. La segunda vuelta se celebró el domingo siguiente, 26 de octubre, para aquellos candidatos a delegados que no alcanzaron más del $50 \%$ de los votos válidos en la primera votación. Ver Juventud Rebelde, La Habana, 19-X-97. Pág. 1.

66. Granma, "Estudiarán escolares documentos del V Congreso del Partido". La Habana, 30-X-97. Pág. 2.

67. Granma, "Estudio y aplicación de los documentos del V Congreso del Partido, desde diciembre”. La Habana, 13-XI-1997. Pág. 1. 68. El País, Madrid, 5-X-97. Pág. 3. 


\section{RESUMEN}

El artículo describe de forma prolija el desarrollo y resultados del V Congreso del Partido Comunista de Cuba celebrado en La Habana en octubre de 1997. Por el papel hegemónico del Partido Comunista Cubano en el sistema político cubano, las conclusiones del citado congreso pueden ser interpretadas como elementos claves de reflexión en el marco de la situación económica y política de Cuba.

Palabras claves: Congreso, informe, situación económica, organización partidista, capitalismo, ideología

\section{ABSTRACT}

This article describes in a detailed manner the development and results of the $\mathrm{V}$ Congress of the Communist Party of Cuba, which was celebrated in Havanna in October 1997. Due to the crucial role of the Communist Party in Cuba, this article analyses crucial components of the current Cuban political and economic situation.

Key words: information, economic situation, party organization, capitalism, ideology.

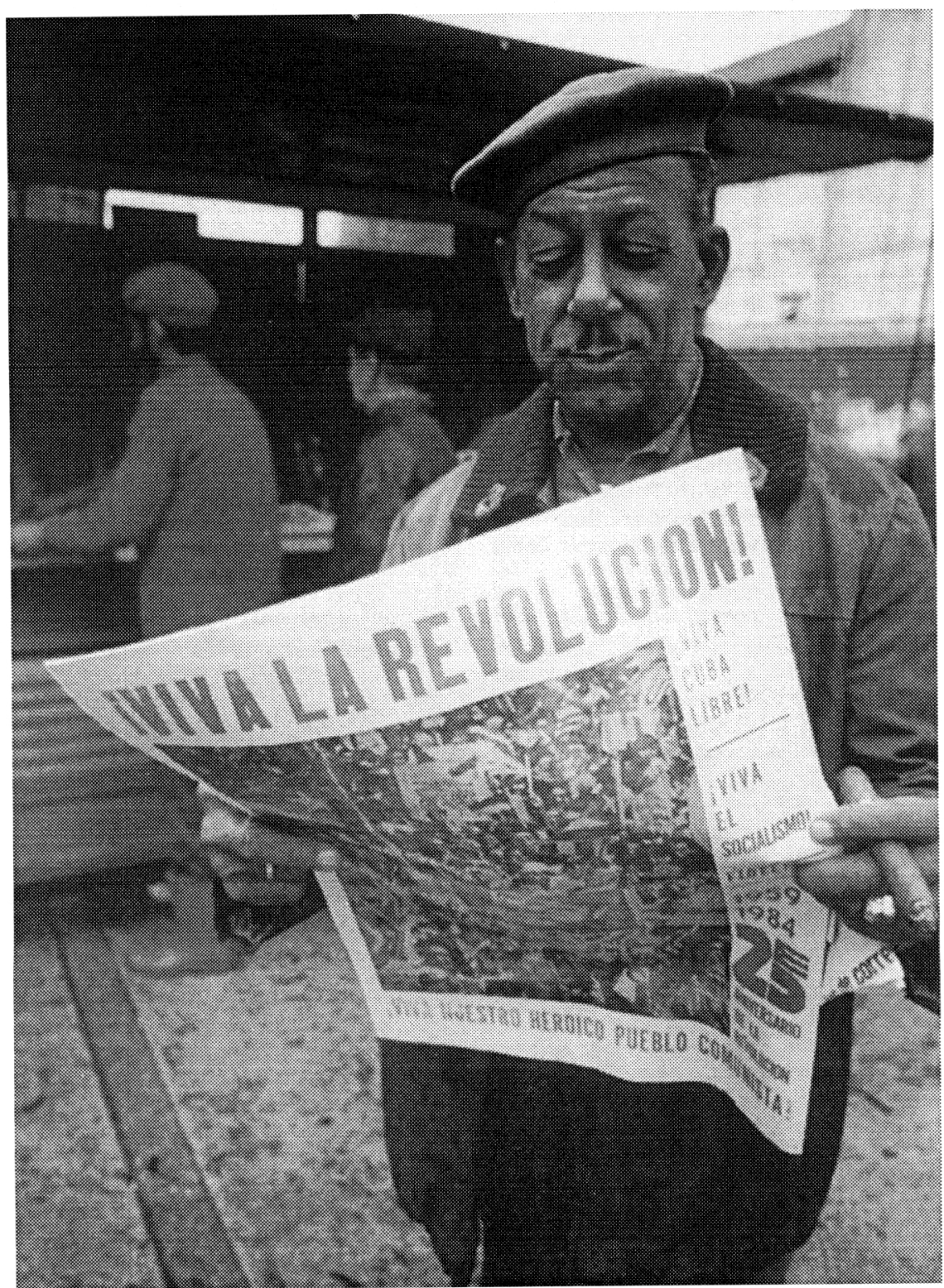

